\title{
FEMINISMOS EM DEBATE: DISPUTAS, CONTRADIÇÕES E TENSÕES (1930-1937)
}

\author{
FEMINISMS IN DEBATE: \\ DISPUTES, CONTRADICTIONS AND TENSIONS (1930-1937)
}

DOI: http//dx.doi.org/10.15448/2178-3748.2017.2.23904

\author{
Iracélli da Cruz Alves \\ Doutoranda em História - Universidade Federal Fluminense (UFF) \\ iracelli_alves@hotmail.com
}

\begin{abstract}
RESUMO: O artigo analisa a militância feminista de um grupo de mulheres do Partido Comunista do Brasil, atualmente denominado Partido Comunista Brasileiro (PCB) entre 1930 e 1937, bem como as relações estabelecidas com outros grupos feministas do período. A preocupação central é evidenciar a forma como as pecebistas concebiam a luta e as críticas que fizeram a outros grupos feministas. No início do século XX, tornouse crescente o número de mulheres organizadas em prol de mudanças político-sociais para o gênero feminino. No período, surgiram organizações feministas que lutaram por mais direitos para as mulheres. A luta pela emancipação feminina era permeada por tensões. Uma parcela das mulheres do PCB entendia o feminismo como um movimento "pequeno-burguês", por isso, inadequado para as mulheres que estavam verdadeiramente preocupadas com a emancipação feminina. Não se assumir feminista não significava, necessariamente, falta de engajamento com as pautas comuns aos feminismos. Afora todas as tensões, a luta das mulheres dentro do PCB e as relações intrapartidárias também foram marcadas por tensões e contradições. Nesse sentido, o texto visa refletir sobre parte do debate presente nas lutas feministas na primeira metade do século XX.
\end{abstract}

PALAVRAS-CHAVE: Mulheres. Política. Feminismos.

ABSTRACT: This article analyzes the feminist activism of women from Communist Party of Brazil, now called Brazilian Communist Party (BCP) between 1930 and 1937, as well as the relationships established with other feminist groups of the period. The central concern is to show how the women that composed the party conceived the fight and the criticisms they made to other feminist groups. In the early twentieth century the number of organized women rose in support of political and social change for females. In the period, it grown up formal collective organizations that fought for more rights for women. The struggle for women's emancipation was permeated by tensions. A portion of women from BCP understood feminism as a "petty bourgeois" movement, therefore, inappropriate for women who were truly concerned with women's emancipation. Do not recognize herself feminist does not mean, necessarily, lack of engagement with the common schedule to feminisms. Aside from all the tensions, the struggle of women into BCP, and intraparty relations, had also been marked by tensions and contradictions. In this sense, the text aims to reflect on part of discussion in feminist struggles in the first half of the twentieth century.

KEYWORDS: Women. Policy. Feminisms. 
No Brasil do século XIX, algumas mulheres manifestaram-se em prol da emancipação feminina através de jornais e revistas de grande circulação e/ou de grupos políticos específicos, bem como os editados por elas mesmas. Por meio da imprensa, buscaram incitar mudanças nos status econômico, social, cultural e legal das mulheres. Nas primeiras décadas do século XX, com a implantação da República, tornou-se crescente o número de mulheres organizadas visando mudanças político-sociais para o gênero feminino. Nesse período, surgiram algumas organizações feministas com diferentes práticas políticas.

Atualmente, entende-se por feminismo as práticas sociais, culturais, políticas e linguísticas que atuam com o objetivo de liberar as mulheres de uma cultura misógina e da imposição de um modo de ser construído pela lógica masculina nos marcos da heterossexualidade (RAGO, 2013, p. 28). Mas no início do século XX, geralmente o termo feminismo designava as mulheres de tendências liberais de classe média que, na maior parte das vezes, não se aprofundaram na discussão acerca das estruturas sociais de dominação masculina (RAGO, 2001, p. 219).

O que não significa dizer que, na prática, elas não estivessem corroendo as estruturas de dominação. Não deve ter sido fácil para as mulheres daquele contexto, independente do seu lugar de classe, se assumirem feministas. Certamente, frequentar espaços ocupados majoritariamente por homens, como as universidades, não foi um processo tranquilo. $\mathrm{O}$ caso da médica baiana Francisca Praguer Froes é bem representativo das barreiras que as mulheres dos estratos sociais economicamente mais elevados tiveram de transpor. No final do século XIX, quando decidiu estudar medicina, ela enfrentou problemas relacionados à segregação sexual, à época, presentes no ensino superior brasileiro, "um deles era o que obrigava as estudantes a assistirem as aulas devidamente acompanhadas, sentando-se em cadeiras separadas dos colegas homens" (RAGO, 2007a, p. 120).

Todas estas experiências de mulheres que romperam com a lógica dos espaços desenhados e planejados pela arquitetura masculina contribuíram para o desenvolvimento de uma consciência feminista surpreendente para o seu tempo e espaço. O que não significa dizer que houve uma adesão uníssona, homogênea e automática. As ações dos sujeitos não são baseadas apenas em escolhas individuais. Refletem, também, as aspirações e os interesses de uma camada ou classe social (RAGO, E. 2007, p. 28-29). Os movimentos feministas no Brasil foram resultado de um processo gradual, às vezes promovido individualmente, outras de maneira coletiva. 
Um dos grupos feministas de grande expressão no Brasil foi a Federação Brasileira pelo Progresso Feminino (FBPF), liderada por Bertha Lutz (1894-1976). A Federação foi oficialmente inaugurada em 09 de agosto de 1922. Teve como questão central, mas não única, a incorporação da mulher como sujeito portador de direitos políticos. Organização de nível nacional, alcançou uma institucionalização surpreendente. Surgiram filiais da FBPF em vários estados brasileiros, como São Paulo, Bahia e Pernambuco, assim como outras associações assistenciais e profissionais se uniram à entidade (PINTO, 2003, p. 14).

Este feminismo não questionou as implicações de se atribuir à mulher a responsabilidade total pelas atividades domésticas e pela socialização dos filhos. Não ocorreu uma reformulação no âmbito das obrigações familiares entre os gêneros masculino e feminino. Continuava-se a considerar o espaço doméstico como inerente à mulher, mantendo-se sua posição desigual na sociedade, fonte de um processo de violência contra a sua pessoa. Consequentemente, havia uma tendência para que as mulheres se sentissem divididas, culpadas, quando obrigadas a trabalhar fora do lar; considerando sua atividade profissional como algo secundário em relação à atividade principal de esposa e mãe, dando lugar à discriminação salarial, profissional e sindical. (SOIHET, 2013, p. 27-28).

A vertente do feminismo comandada por Bertha Lutz evitou assumir posições radicais de contestação em relação aos homens, além de contribuir com a mitificação da maternidade, presente nas argumentações em prol da aquisição de direitos. Na opinião de Rachel Soihet (2013, p. 106), os caminhos trilhados por Bertha Lutz e pela federação representaram uma tática. As mulheres reunidas em torno da FBPF, conscientes do tempo e do espaço em que estavam inseridas, seguiram a trilha mais adequada aos seus objetivos. Em uma tentativa consciente de prevenir ataques hostis, as integrantes da federação enfatizaram, com frequência, sua feminilidade.

As mulheres da FBPF faziam parte de um pequeno grupo de mulheres letradas, integradas nas camadas médias e alta da sociedade. Certamente, o lugar de classe condicionou suas ações. Apesar disso, elas estavam conscientes e comprometidas com determinadas mudanças. Mesmo com dificuldades, por não terem sido educadas para tamanhos desafios, souberam enfrentar uma exposição pública e um tipo de crítica, censura e reprovação pelos lugares que decidiram ocupar, já que se distanciavam daqueles pensados para as mulheres do período. A federação abriu um leque de reivindicações bastante amplas, para além do sufrágio feminino. Defendeu desde os direitos sociais da mulher grávida, até garantias legais para o trabalho das mulheres. Algumas criticaram as relações conjugais exigindo mudanças no 
comportamento moral dos homens, sobretudo no que diz respeito a infidelidade no casamento, chegando até a defender o divórcio (VIEIRA, 2002, p. 167-168).

A FBPF não adotou uma postura crítica em relação ao sistema político-econômico vigente. Ao que parece, a organização não tinha a pretensão de abolir a estrutura social de classe, o que não significa que pretendia conservar o status quo. Adotou uma postura reformista e lutou pela obtenção de uma legislação que equiparasse socialmente os sexos e que abrisse às mulheres os caminhos de sua emancipação. Preocupou-se em discutir os problemas enfrentados pelas mulheres da classe trabalhadora, mas não se esforçou em mobilizá-las politicamente (SOIHET, 2013, p. 94-95).

Embora os programas da Federação sempre incluíssem reivindicações de melhora das condições de trabalho das mulheres operárias e da proteção às mulheres grávidas e crianças, seus vínculos diretos com a classe trabalhadora e com as mulheres pobres eram frágeis (SOIHET, 2013, p. 95).

Mas não foram apenas as mulheres da FBPF que se organizaram em prol da luta pela emancipação feminina. Como foi observado, a luta feminista no Brasil foi bastante heterogênea. Do outro lado da arena política, também lutando por melhores condições de existência para o gênero feminino, estavam as mulheres ligadas às esquerdas, a maioria reunida em torno do Partido Comunista do Brasil, atualmente denominado Partido Comunista Brasileiro (PCB). A maior parte delas recusava a adjetivação feminista, provavelmente como uma estratégia de diferenciação em relação às mulheres que elas denominavam burguesas, ligadas a grupos políticos tradicionais. Além disso, não se deve perder de vista o impacto das ideias defendidas pelo PCB que considerava o feminismo como um movimento pequeno burguês. $\mathrm{O}$ partido defendia um movimento feminino por emancipação a partir de um viés classista.

As pecebistas fundaram organizações frequentemente perseguidas. Em 1935 criaram a União Feminina do Brasil (UFB) que, em decorrência do autoritarismo do governo de Getúlio Vargas, sobreviveu por apenas dois meses. Durante o curto período de existência lançou um manifesto convocando as mulheres à luta. A organização defendeu pautas específicas para as mulheres: reivindicou a emancipação feminina; mais acesso à educação formal e que na escola tivessem a mesma formação que os homens; defendeu o fim das disparidades salariais entre os sexos, a partir do princípio do igual salário para igual trabalho e pautou a valorização do trabalho doméstico como trabalho produtivo.

Não poderíamos continuar indiferentes ante os choques, as tragédias e a miséria que nos cercam. Falharíamos a nós mesmas se não pensássemos em 
lutar ombro a ombro com os homens, pelos nossos direitos. Qual tem sido até hoje nosso papel no Brasil? Na escola, a opressão dos que querem fazer de nossa inteligência um sabujíssimo. Na fábrica, substituindo o homem com salários menores e menor revolta. No escritório produzindo tanto quanto um homem e recebendo muito menos que ele. No lar, prisioneiras passivas, tudo criando e nada produzindo. Na sociedade, joguetes cheios de deveres, tudo se nos exigindo, sem direitos, tudo se nos negando. [...] Lutemos Unidas! E, para essa luta, chamemos todas as mulheres do Brasil. Operárias, intelectuais, estudantes, artistas, professoras, jornalistas, comerciárias, bancárias, telefonistas, domésticas, camponesas, costureiras, funcionárias, mulheres que trabalham em todos os setores. [...] Lutemos unidas pelos nossos direitos, por melhores salários e ordenados, pelo nosso direito de viver. (Diário da Bahia, 03/07/1935, p. 3).

O PCB foi fundado em 25 de março de 1922. Era majoritariamente formado por lideranças do movimento operário oriundas do anarquismo, influenciadas e empolgadas com a Revolução Russa de 1917. O partido pretendia seguir os princípios do marxismo-leninismo, buscando encontrar o que pensava ser o "justo caminho da revolução no Brasil" (SENA JUNIOR, 2009, p. 42). Na trilha do ideal revolucionário, na década de 1930 parte das mulheres que se organizou em torno do PCB defendeu a emancipação feminina. Frequentemente, suas denúncias giravam em torno da exploração do trabalho de forma geral e do trabalho feminino de maneira particular. Acreditavam que a subjugação do sexo feminino estava associada ao modo de produção capitalista. De forma geral, entendiam que a emancipação feminina só seria possível com o fim da sociedade estruturada em classes sociais. (PINTO, 2003, p. 15).

A UFB pretendia integrar mulheres das mais diferentes classes sociais e se pronunciou abertamente contra o sistema político vigente. Se comportaram de forma diferente daqueles ligadas a FBPF, que utilizaram a tática de alianças com os grupos políticos dominantes e não mobilizaram politicamente as mulheres das classes subalternizadas.

Ao contrário de outras organizações femininas que surgiram em nosso país, umas inócuas, outras nitidamente ligadas a correntes políticas partidárias, explorando demagogicamente a angustiosa situação da mulher ou pregando um estreito feminismo que consiste em combater o homem em si e nele ver um "inimigo" da mulher, a UNIÃO FEMININA DO BRASIL, iniciativa de um grupo de trabalhadores manuais e intelectuais, diferencia-se inteiramente de todas as organizações já existentes, pelo seu absoluto desacordo com os programas e normas de ação dessas associações. (Diário da Bahia, 03/07/1935, p. 3)

Embora as militantes da UFB tenham destacado que a organização se diferenciava dos outros grupos femininos, na prática elas defenderam pautas muito semelhantes, a exemplo da defesa da igualdade salarial, do acesso à educação formal, entre outros. Ademais, assim como as mulheres da FBPF, muitas vezes, as comunistas contribuíram para a mitificação da 
maternidade (ALVES, 2015, p. 96-97). Entretanto, seguindo a linha do ideal revolucionário, adotaram táticas diferentes. As diferenças estavam relacionadas aos diversos projetos políticos em disputa. Se de um lado havia mulheres que acreditavam que as conquistas só seriam possíveis com o apoio dos grupos políticos no poder, outras buscaram se organizar distantes do poder institucional. As feministas de esquerda procuraram se contrapor a um modelo de feminismo que entendia que a luta pela libertação das mulheres só poderia ser empreendida pelo sexo feminino.

Apesar do curto tempo de existência houve uma tentativa da instalação de uma filial baiana da União Feminina do Brasil. O jornal Diário da Bahia promoveu propagandas da entidade, indicando-a como uma referência para o feminismo. Em 27 de junho de 1935 anunciou os preparativos para a instalação de um núcleo da UFB na Bahia. No dia seguinte noticiou, em primeira página, uma reportagem sobre a presença de uma das diretoras da organização no Estado da Bahia, Mary Martins (SIQUEIRA, 2009, p. 104-107).

As publicações deixam em evidência o caráter da UFB e o esforço que a organização fez em se distanciar da FBPF, inclusive descrevendo de forma negativa os trabalhos da federação. As mulheres da UFB destacaram que os caminhos para uma verdadeira libertação feminina estavam nos movimentos populares e que as mulheres não deveriam confiar em "líderes feministas".

A mulher do Brasil já começa a perceber que a luta por sua libertação tem suas bases nos movimentos populares e não confia mais em "líderes feministas". A mulher já começa a compreender que as Berthas Lutz, uma vez instaladas no poder, pouco se lembram das plataformas "feministas" gritadas em praça pública, a fim de arrastar as massas femininas". (Diário da Bahia, 04/07/1935, p. 1).

No dia 23 de julho algumas mulheres da UFB foram presas. A partir de então as publicações no Diário da Bahia sobre a UFB passaram a ser escassas e mudaram de teor. O periódico passou a publicar denúncias, prisões e apelações, informando sobre a descoberta das "reais intenções" daquele núcleo. A última reportagem sobre o tema foi publicada em janeiro de 1936, apresentando informações de um agente secreto que se infiltrou numa das reuniões da UFB no Distrito Federal (SIQUEIRA, 2009, p. 108).

A reunião foi realizada no Rio de Janeiro e o relatório produzido em outubro de 1935. Segundo o "investigador 588", o objetivo desta reunião era organizar um movimento contra a guerra e o fascismo. De acordo com o informante: 
A assembleia fora convocada por um grupo de mulheres chefiado pelas senhoras: Eugênia Álvaro Moreira, Lydia Freitas, Armanda Álvaro Alberto, Laudimira Trotta, Itália Fausta, Ivetta Ribeiro, e outras, com o fim de organizar um comitê de propaganda e luta contra a guerra. (Diário da Bahia, 10/01/1936, p. 2).

Acrescentou, ainda, que estavam presentes 40 mulheres e uns 20 homens. De acordo com o relatório:

\begin{abstract}
Algumas mulheres usaram linguagem moderna. [...] Eugênia Álvaro Moreira atacou violentamente o fascismo e o integralismo, [...] aconselhando a campanha contra a guerra e o fascismo por todos os meios e lugares, dizendo que à mulher competia a maior propaganda por ser ela a maior e mais explorada vítima da sociedade atual. [...] Usou depois a palavra a senhora Maria Lacerda de Moura [que] expõe sua opinião individual, dizendo que a única maneira de acabar com as guerras é fazer a greve da natalidade recusando-se as mulheres a conceber filhos que iriam servir de carne para canhão (Diário da Bahia, 10/02/1936, p. 2).
\end{abstract}

Além de sugerir a "greve de natalidade" como tática de luta contra a guerra, Maria Lacerda de Moura asseverou que a Cruz Vermelha representava uma "arma de guerra", "agente do imperialismo", que curava os feridos "para os lançarem novamente no inferno da guerra". Segundo o investigador, as palavras de Maria Lacerda de Moura causaram mal-estar. A senhora Ivetta Ribeiro, membro da Cruz Vermelha, "defendeu-se dos ataques de Maria Lacerda de Moura, sendo suas palavras aplaudidas pela maioria”. (Diário da Bahia, 10/01/1936, p. 2)

Considerando o clima cultural da época, em que a atividade política das mulheres era vista com desconfiança, é possível que a narrativa do investigador tenha um teor depreciativo da reunião política feminina. Apesar disso, também é correto que havia pontos de tensão tanto entre grupos diferentes, quanto dentro deles. Em que pesem as diferenças, podemos dizer que as reivindicações das feministas ligadas às esquerdas não se restringiram às questões da política formal e trabalhista.

Maria Lacerda de Moura, uma das figuras mais importantes do anarquismo brasileiro, criticou a dupla moral vigente, a forma de organização da família com seu complemento, a prostituição, preocupando-se em discutir outras questões tabus à época, como a sexualidade e o corpo. Mais do que a emancipação das mulheres, Maria Lacerda de Moura advogou pela construção de novos sujeitos éticos capazes de criar formas de sociabilidade, pautadas na solidariedade, no amor ao próximo e no respeito à diferença. Seus escritos mais contundentes dizem respeito à ética, à educação e às dificuldades que as mulheres brasileiras enfrentavam. No decorrer de sua trajetória político-intelectual participou de diversos grupos feministas - 
inclusive divergentes - como a FBPF e a UFB, e escreveu uma quantidade significativa de livros, artigos e folhetos em que denunciava as múltiplas formas de dominação burguesa, da opressão masculina e da exploração capitalista do trabalho. Vários de seus textos podem ser encontrados em revistas anarquistas internacionais, publicadas na Espanha e na Argentina entre as décadas de 1920 e 1930 (RAGO, 2007b, p. 275-293).

Pode-se dizer que, antecipando o que será o grande centro de investimento do movimento feminista da década de 1970 - a saber, a questão dos direitos de reprodução e da violência doméstica -, Maria Lacerda, ao lado de outras anarquistas, denuncia o 'contrato sexual' implícito no contrato social, que exige o direito ao corpo e ao prazer sexual das mulheres. Segundo ela, a sociedade estabelece partilhas profundamente nocivas ao desenvolvimento humano, pois assentadas na escravidão da mulher e no servilismo dos fracos. Nesse sentido, o casamento monogâmico beneficiaria exclusivamente o homem, e não a mulher. (RAGO, 2007b, p. 283).

Apesar de ter criticado a ordem capitalista, na década de 1930 as ideias de Maria Lacerda de Moura foram rebatidas por Patrícia Galvão, mais conhecida como Pagu, à época, militante do PCB. Talvez pela atenção que deu às questões ligadas à sexualidade, problemas, que no contexto, eram secundarizados pelo partido. Nas palavras de Patrícia Galvão:

Temos a atrapalhar o movimento revolucionário do Brasil uma elitezinha de «João Pessoa» que sustentada pelo nome de vanguardistas e feministas berra a favor da liberdade sexual, da maternidade consciente, do direito do voto para «mulheres cultas» achando que a orientação do velho Malthus resolve todos os problemas do mundo. Estas feministas de elite, que negam o voto aos operários e trabalhadores sem instrução, porque, não lhes sobra tempo de trabalho forçado a manutenção dos seus filhos, se esquece que a limitação de natalidade quase que já existe mesmo nas classes mais pobres e que os problemas todos da vida econômica e social ainda estão para ser resolvidos. Seria muito engraçado que a ilustre Maria Lacerda de Moura fosse ensinar a lei de Malthus ao sr. Briand, para que ele evitasse a guerra mundial atirando a boca ávida dos imperialistas gananciosos, um punhado de livros sobre maternidade consciente (Homem do Povo, 27/03/1931, p. 2).

No artigo, Pagu acusa Maria Lacerda de Moura de "sargento reformista que precisa estender sua visão para horizontes mais vastos". A caracterização feita pela autora minimiza a atuação política e as lutas travadas pela anarquista. Considerando os padrões do período, é razoável afirmar que Moura adotou posturas extremamente radicais na defesa da libertação das mulheres. Mas para Pagu, as ideias defendidas por Maria Lacerda de Moura não eram urgentes naquele contexto. Segundo ela, os problemas enfrentados pelas mulheres se vinculavam à “questões maiores", leia-se, a divisão da sociedade em classes sociais. 
As palavras de Pagu evidenciam um pensamento muito comum entre os pecebistas do período, que relacionavam o problema da opressão feminina à estrutura da sociedade capitalista, dividida em classes sociais. Defendiam que quando o capitalismo fosse substituído pelo socialismo, todas as diferenças sociais se dissolveriam. Apesar dessa perspectiva mais geral, dentro do próprio partido havia contendas acerca dessas questões. Ao longo do tempo, esse debate foi se tornando mais amplo e complexo. ${ }^{1}$

O texto de Pagu põe em relevo a complexidade das relações entre as mulheres que lutavam pela emancipação feminina. No contexto, disputas políticas estavam em jogo. Forjaram-se diferentes pontos de vista sobre o encaminhamento da luta das mulheres e dos principais meios de opressão do sexo feminino. Através do romance Parque Industrial, livro de objetivos políticos demarcados, Patrícia Galvão, agora sob o pseudônimo de Mara Lobo, criou personagens que visavam representar as mulheres operárias e pobres, vítimas do machismo e da exploração de classe.

Ao representar o cotidiano das trabalhadoras nas fábricas, Mara Lobo denunciou as arbitrariedades e as humilhações a que estavam submetidas e evidenciou a hipocrisia das classes dominantes, que se materializava, também, na arte. Considerado panfletário, no que foi amplamente criticado à época, o livro inaugurou uma literatura política de militância partidária, cujo valor só passou a ser ressaltado depois (MORAES, 2007, p. 231).

Ideologicamente alinhado ao Partido Comunista do Brasil, publicado em 1933, o livro escrito por volta de 1932, tem sua narrativa centrada no cotidiano de um bairro operário de São Paulo, o Brás. No livro, a autora criticou, além da exploração de classe, a dupla moral vigente e suas possíveis consequências para as mulheres, como a prostituição, o aborto e o assédio moral e sexual a que estavam expostas em uma sociedade burguesa e machista, como evidencia a passagem abaixo:

O confete vai da cabeça pro chão. Do chão pra cabeça.

- Olha o bando! Olha o bando! Chiquita!

- As meninas atiram-se como gatas pegando os rolos de serpentina.

Os sexos estão ardendo. Os grilos estrilam nos sinais. Os burgueses passam nos carros concordando que o Brás é bom no carnaval.

No Colombo, as damas brancas, pretas ou mulatas como as meninas fugidas de casa, não pagam entrada. [...] Todas as meninas bonitas estão sendo bolinadas. Os irmãozinhos seguram velas a troco de balas. A burguesia procura no Brás carne fresca e nova.

- Que pedaço de italianinha!

\footnotetext{
${ }^{1}$ A análise das tensões sobre a "questão feminina" existentes no PCB e nas organizações femininas ligadas ao partido foram explorados na dissertação de mestrado intitulada A política no feminino: uma história da militância feminina no partido Comunista do Brasil - Seção Bahia (1942-1949) (ALVES, 2015).
} 
- Só figura. Vá falar com ela. Uma analfabeta.

- Pruma noite, ninguém precisa saber ler (LOBO, 2006, p. 43-44).

Por meio de sua narrativa Mara Lobo deixou transparecer parte de seu pensamento acerca dos problemas sociais enfrentados pelas mulheres. Para ela, muitas das "aventuras" que faziam parte do aprendizado sexual dos jovens ricos tinham consequências graves, como gravidez e nascimentos indesejados. Problema que afetava desastrosamente as mulheres, pois os pais frequentemente negavam a paternidade, levando-as, muitas vezes à prostituição, tal qual ocorreu com a personagem Corina, que se envolveu com Alfredo, um burguês, e engravidou. Como o pai não assumiu a paternidade, Corina se desesperou ao perceber-se desempregada e diante de um moralismo hipócrita, inclusive dentro de sua classe social. Por isso, acabou se entregando à prostituição.

As garotas cochicham com risinho - Viu Otávia? A Corina de Barriga! Juro que está!

Uma delas vai linguarar para a madame. A costureira chama a mulata. Todas se alvoraçam. É uma festa paras meninas. Ninguém sente a desgraça da colega. (LOBO, 2006, p. 51).

$*$

Chega cedo. Senta-se num banco do Anhangabaú. O automóvel com duco novo para. É o seu amor. [...] Conta-lhe como saíra da vila Simeone. Não quisera abortar. Madame pusera-a para fora do emprego.

[Ele] deixa cair uma nota e grita desembraiando:

- Não perca! São cem paus!

A baratinha fonfona a ilusão de Corina.

Ficou um trapo no Anhangabaú. Meia dúzia de choferes comentam a gravidez e as pernas sem meias. A chuvinha que cai é maior do que o choro dela. Desbota a chita de grandes bolas. Com sua mãe foi assim mesmo! [...] Um bando álacre se diverte na chuva. Três homens e uma mulher. A pé. Convidam-na por troça. Corina adere, vai junto. Como máquina. Se embebeda, fuma. [...] Se excita. Quer todos os machos de uma vez. No dia seguinte, um sujeito lustroso a leva para um bordel no Brás (LOBO, 2006, p. 53-54).

O desfecho da história de Corina é interessante. É possível notar que a narradora funde opressão de gênero e de classe. As representações indicam uma reprodução sócio cultural de geração. Corina, filha de mulher pobre, acaba tendo o mesmo destino de sua mãe, igualmente pobre, que se tornou mãe solteira e, consequentemente, prostituta.

Aparece fortemente na narrativa a ideia de prostituição como um mal social gerado pelo capitalismo. Hoje este olhar pode ser problematizado. Como demonstrou Margareth Rago (2013, p. 112-279), são grandes os desencontros entre as prostitutas que se organizam 
politicamente e algumas feministas. As abolicionistas, por exemplo, lutam para acabar com a prostituição em vez de regulamentar suas práticas, pauta defendida por muitas prostitutas brasileiras. Mas na década de 1930 os mais variados setores da sociedade eram praticamente unânimes em perceber a prostituição como um problema a ser combatido. Tendo em vista os problemas enfrentados pelas mulheres trabalhadoras, em que a prostituição aparecia com um dos mais sérios, Mara Lobo buscou denunciar os limites do feminismo considerado pequenoburguês. Provavelmente, aquele liderado por Lutz, que tinha maior visibilidade no período.

Acorda com o alvoroço de mulheres entrando. São as emancipadas, as intelectuais, e as feministas que a burguesia de São Paulo produz. [...]

- Hoje é a conferência. Mas acho melhor mudar a hora das reuniões. Para podermos vir aqui!

- Será que Lili Pinto vem com o mesmo tailleur?

- Ignóbil!

- Ela pensa que a evolução está na masculinidade da indumentária. [...]

O barman cria cocktails ardidos. As ostras escorregam pelas gargantas bem tratadas das líderes que querem emancipar a mulher com pinga esquisita e moralidade. Uma matrona de gravata e grandes miçangas aparece espalhando papeis.

- Leiam. O recenseamento está pronto. Temos um grande número de mulheres que trabalham. Os pais já deixam as filhas serem professoras. E trabalhar nas secretarias... Oh! Mas o Brasil é detestável no calor. Ah! Mon Palais de Glace! - Se a senhora tivesse vindo antes, podíamos visitar a cientista sueca...

- Ah! Minha criada me atrasou. Com desculpas de gravidez. Tonturas. Esfriou demais o meu banho. Também já está na rua! [...]

- O voto para as mulheres está conseguido! É um triunfo!

- E as operárias?

- Essas analfabetas. Excluídas por natureza. (LOBO, 2006, p. 76-78)

A narrativa antecipa uma crítica levantada mais fortemente no movimento feminista brasileiro na década de 1980, qual seja, a exploração de classe presente entre as mulheres, demonstrando que os sujeitos são atravessados por várias identidades que se sobrepõem. Esta problemática influenciou a produção acadêmica, que passou a dar mais atenção a chamada relação intragênero. Rachel Soihet (2013, p. 95), ao assinalar o paradoxo do feminismo da FBPF, sinalizou que para algumas feministas se dedicarem às suas profissões e/ou atividades políticas lançavam mão do trabalho das empregadas domésticas, tipo de atividade desenvolvida por mulheres pobres que, na maioria das vezes, recebiam baixíssimos salários. Décadas antes, Mara Lobo não deixou de se colocar contra este tipo de exploração, que se configurou como exploração de classe. "Ah! Minha criada me atrasou. Com desculpas de gravidez. Tonturas. Esfriou demais o meu banho. Também já está na rua!”(LOBO, 2006, p. 78).

Indo além, ao descrever a relação entre mulheres ricas e de classe média e mulheres trabalhadoras, a narradora evidenciou o que considerava os limites do feminismo burguês. No 
trecho citado acima, no momento do diálogo em que uma feminista comenta as vestes de uma companheira - "-Será que Lili Pinto vem com o mesmo tailleur"; "-Ela pensa que a evolução está na masculinidade da indumentária " - a narradora representou as feministas como mulheres frívolas, preocupadas com coisas completamente fúteis e sem relevância social.

O trecho é elucidativo pelo esforço de desmascaramento das contradições do feminismo, percebido pela autora como desvios pequeno-burgueses. Mara Lobo considerou que entre as feministas faltava uma preocupação no que diz respeito à emancipação das mulheres operárias, descritas como analfabetas, portanto, naturalmente excluídas. Todavia, como foi demonstrado, o trabalho da Federação Brasileira pelo Progresso Feminino teve sua relevância social e histórica. A narrativa de Mara Lobo está ligada ao posicionamento político da autora e à forma como interpretava a ação das feministas.

Entretanto, as representações constantes no romance não destoam por completo da realidade. As criações de Mara Lobo podem estar relacionadas às interpretações que a autora fez dos discursos feministas correntes entre alguns grupos. Edith Gama e Abreu, por exemplo, se pronunciou contra as medidas tomadas pelo governo Vargas em 1931, que restringiu o voto feminino. O código eleitoral provisório editado pelo governo estabelecia que apenas mulheres de determinados grupos poderiam votar, quais sejam, solteiras ou viúvas com renda própria ou as mulheres casadas autorizadas pelo marido. Muito restritamente, privilegiava uma pequena parcela de mulheres trabalhadoras. Diante da medida, Edith Gama e Abreu deixou transparecer seus preconceitos de classe. A líder feminista se pronunciou contrária à medida, questionando:

Como pôr-se acima do trabalho altruístico a atividade obrigada pelas circunstâncias? Como o descortino mental de uma mulher culta pode ser vencida pela energia material de uma operária na colaboração política de um povo? Não que eu me ajuste às doutrinas de superioridades de classes. Apegome, sim, à teoria da conferição de direitos pela equivalência das aptidões $(O$ Imparcial, 18/09/1931 apud VIEIRA, 2002, p. 108).

A luta pela emancipação feminina era permeada por tensões. Podemos dizer que para as mulheres do PCB o feminismo era entendido como um movimento pequeno-burguês, por isso, inadequado para as mulheres que estavam preocupadas, de fato, com a emancipação feminina. Afora todas as tensões existentes entre as mulheres pecebistas e as demais organizações feministas, a luta das mulheres dentro do Partido e as relações intrapartidárias também foram marcadas por tensões e contradições. Os indivíduos que compuseram a esquerda, apesar de todo o projeto comum de mudar a ordem social e cultural burguesa não ficaram imunes as ideologias machistas. A própria Patrícia Galvão, após alguns anos de militância, se sentiu vítima do que 
considerou uma "manipulação sexual" e "autoritária" promovida pelos dirigentes pecebistas, que reservaram a algumas militantes papéis que, considerando os padrões morais vigentes, eram extremamente humilhantes. Entre eles, o de colher informações a partir de atividades sexuais, fato que a deixou indignada.

Estou de acordo com o sacrifício total, se se tratasse de uma coisa que valesse a pena, se se tratasse de vidas, num momento de luta armada, em plena revolução. Mas assim, para obter ridículas informações, que nem sequer se sabe se serão aproveitadas, eu acho que é exigir demais das mulheres revolucionárias. Eu não sou prostituta. [...] Pensam que uma aventura a mais ou a menos para mim não tem importância nenhuma. Uma mulher de pernas abertas: é o que vocês pensam. (GALVÃO apud FERRAZ, 2005, p. 226-227).

Patrícia Galvão se indignou com as imposições dos companheiros de militância, apesar de, desde muito cedo, ter contrariado a moral vigente:

O primeiro fato distintamente consciente da minha vida foi a entrega do meu corpo. Eu tinha doze anos incompletos. Sabia que realizava qualquer coisa importante contra todos os princípios, contrariando a ética conhecida e estabelecida. Com certeza, havia uma necessidade, mas não era nenhuma das chamadas necessidades, ou melhor, a necessidade nada tinha a ver com a entrega fisiológica do corpo. Antes desse fato, só lembro da inquietação anterior. Não havia falta de compreensão do ambiente. Isso só depois comecei a sentir. Toda a minha vida. Naquele tempo eu é que não compreendia o ambiente. Em me lembro que me considerava muito boa e todos me achavam ruim. As mães das outras crianças não queriam que eu brincasse com suas filhas. [...] Eu nunca consegui perceber minha perversidade. Tinham me feito assim e jogado em paredes estranhas. Andava então sozinha. (GALVÃO apud FERRAZ, 2005, p. 53).

Apesar desta aparente rebeldia e da necessidade de distinção frente a moral burguesa, que nas memórias da autora aparecem como precocemente desenvolvidas, ela se rebelou contra o tratamento dispensado por alguns companheiros de partido que a trataram como prostituta, que venderia seu corpo em troca de informações.

Os limites entre liberdade sexual e desrespeito ao indivíduo eram muito tênues. Nas descrições de Patrícia Galvão, os homens do partido, muitas vezes, interpretavam mal o discurso emancipacionista de algumas companheiras, achando que as mesmas estavam dispostas a qualquer atividade sexual. Ela descreveu com revolta e indignação a investida sexual de um companheiro: "Como era revoltante e ridículo despir a capa comunista. Que nojo ao vêlo atirar-se a minha procura com a vulgaridade brutal e desastrada que eu já conhecia nos homens de outras classes sociais!” (GALVÃO apud FERRAZ, 2005, p. 87). 
Não foi fácil para as mulheres lutarem politicamente em um contexto marcado por uma cultura falocêntrica. Em qualquer grupo político encontraram resistências e dificuldades para dar encaminhamento à luta pela emancipação do gênero feminino. $O$ golpe que culminou no Estado Novo tornou a luta ainda mais difícil. Para Céli Regina Pinto (2003, p. 38), o golpe de 1937, que culminou na ditadura varguista, matou o embrião da organização da sociedade civil brasileira nesse período.

Ao contrário do que propõem a autora, as fontes evidenciam que a ditadura do Estado Novo (1937-1945) não conseguiu matar o embrião das organizações de grupos insatisfeitos com o status quo. Certamente que a implantação da ditadura desarticulou e/ou enfraqueceu muitos grupos políticos, o que não significa que a luta tenha sido abortada. Ainda que com dificuldades organizativas, nem toda a sociedade brasileira assistiu apática às atrocidades da ditadura. A Federação Brasileira pelo Progresso Feminino, por exemplo, em que pesem as dificuldades, continuou em atividade. Na Bahia, permaneceu atuando por, pelo menos, dez anos após o Golpe de 1937 (VIERIA, 2002, p. 116). Entre as comunistas, o trabalho também não cessou. Por estarem distantes dos grupos políticos dominantes e alinhadas politicamente à esquerda, elas sofreram as mais duras perseguições. Como os homens, mofaram nos cárceres da ditadura varguista e estiveram expostas a toda sorte de humilhações, torturas físicas e psicológicas.

Essa barulhada é que fez com que Olga e Sabo, assim era chamada Elisa Ewert, nos abraçassem emocionadas, pois se achavam entre amigos [...]. As barbaridades a que Sabo fora sujeita iniciavam-se às $3 \mathrm{~h}$. da madrugada, na Polícia Especial. Na primeira noite em que ela e Olga dormiram na Sala 4 todas acordamos com gritos. Olga era a primeira a acudir. Em seus braços Sabo se acalmava (WERNECK, 1988, p. 69)

Não obstante o perigo, não deixaram de trabalhar. Umas na própria prisão, outras na retaguarda, fazendo ligação entre os encarcerados e o mundo exterior, surpreendendo seus companheiros, contrariando as expectativas da suposta fragilidade feminina, a exemplo de Heloísa Medeiros Ramos (1910-1999). Como lembrou Graciliano Ramos (1986, p. 268-274):

Minha mulher chegara e prometia visitar-me na segunda-feira, entre dez e onze horas - Que estupidez! Percebi no aviso a ameaça de aborrecimentos e complicações inevitáveis. Imaginei a pobre, desarmada e fraca, a mexer-se à toa na cidade grande, a complicar-se no aparelho burocrático, enervando-se nas antecâmaras das repartições, mal se orientando nas ruas estranhas, fiscalizadas por investigadores. [...] Enganei-me. Estancando o pranto leve, enxutos os olhos, fez um resumo dos seus atos, na aparência convicta de uma aprovação que não existia em mim. Ofereci-lhe concordância tácita. Que havia de fazer? Tudo aquilo era disparate, mas estava realizado e tornei-me cúmplice 
dele. [...] Inclinava-me a concordar, perceber na mulher energia e resolução, qualidades imprevistas a revelar-se na hora difícil.

Já as encarceradas, se movimentavam como podiam e não deixavam de debater os problemas sociais enfrentados pelas mulheres. De acordo com Maria Werneck (1988, p. 73):

Na Sala 4 havia mulheres cujo pensamento já evoluíra para examinar questões sociais, econômicas, e não somente combater o "não ficarmos à beira do fogão". [...] Nossas conversas, girando em torno de problemas universais, só abordavam o problema feminino nesse conjunto. Naquele momento, tanto atingindo a mulher como a população, nosso maior objetivo era lutar contra o nazi-fascismo na Europa, o integralismo no Brasil.

Os indícios apontam que, apesar da forte repressão promovida pelo Estado Novo, algumas mulheres continuaram se movimentando politicamente, certamente enfrentando muito mais dificultados, pois além de contarem com os empecilhos de uma cultura machista, tiveram de lidar com o aparato repressivo estado novista. Mas esse debate foge a alçada do presente texto. Aqui, pretendeu-se mostrar o processo de luta das mulheres na década de 1930, antes da implantação da ditadura do Estado Novo.

Em linhas gerais, percebe-se que durante o período a luta das mulheres foi marcada por grupos divergentes, embora houvesse consenso no que diz respeito à necessidade de emancipação do gênero feminino. As diferenças se concentravam basicamente nos meios necessários para alcançar a finalidade. Comparando dois grupos políticos expressivos do contexto - a Federação de Mulheres do Brasil e parte das mulheres pecebistas, nota-se que as mulheres da FBPF consideravam que para a emancipação ser conquistada seria fundamental a inserção nos meios políticos institucionais e hegemônicos, para incorporarem as demandas femininas no debate político, apesar de executarem atividades em outras frentes, a exemplo dos trabalhos assistencialistas. Já para as pecebistas, o mais fundamental seria a mobilização das mulheres trabalhadoras. O mais urgente seria resolver as contradições de classe para criar-se as condições concretas para a dissolução das contradições nas relações entre os sexos. Ao mesmo tempo, não deixaram de demarcar as especificidades das mulheres trabalhadoras quando comparadas com os homens da mesma classe.

Fica evidente, portanto, que os feminismos do início do século XX foram marcados por disputas, contradições e tensões decorrentes dos diferentes projetos políticos em disputa. Não obstante, houve oscilações no decorrer do tempo. Se em alguns momentos prevaleceu as disputas entre alguns grupos, como ocorreu na década de 1930; em outros, estes mesmos grupos estabeleceram alianças. Na década de 1940, algumas transformações nos campos político, 
social e cultural contribuíram para mudanças nas relações entre as comunistas e as mulheres assumidamente feministas.

No contexto, as inquietações pela concretização do que consideravam princípios democráticos atingiram maior consenso no seio da sociedade. O PCB adotou a política de União Nacional que, em linhas gerais, defendia as regras do jogo democrático como garantia da transmutação do regime capitalista para o socialista. (DEMIER, 2013, p. 167-168). Diante das transformações, as mulheres do partido passaram a dialogar de maneira mais amistosa com a FBPF. Apesar disso, em 1946, o líder comunista Carlos Marighella descreveu o feminismo como "um falso movimento que se diz disposto a emancipar as mulheres" (O Momento, 05/05/1946, p. 1). Em que pese a representação negativa, as pecebistas se propuseram a fazer alianças com grupos assumidamente feministas, fato que indica alguma autonomia na construção de suas táticas de resistência. As características e os frutos dessa relação só poderão ser analisados em outra oportunidade.

\section{Referências}

\section{Fontes documentais}

ABREU, Edith Mendes da Gama. Restrições inaceitáveis, O Imparcial, Salvador, 18 set. 1931, p. 1 Apud. VIEIRA, Cláudia Andrade. Mulheres de elite em movimento por direitos políticos: o caso de Edith Mendes da Gama e Abreu. 2002. 182 f. (Dissertação) História - Departamento de História. Pontífica Universidade Católica de São Paulo (PUC-SP), São Paulo, 2002. p. 108.

AS MULHERES devem organizar-se para saírem da escravidão. O Momento, Salvador, 05 mai. 1946. p. 1.

EM PROPAGANDA da União Feminina. Diário da Bahia, Salvador, 04 Jul. 1935. p. 1.

FERRAZ, Geraldo Galvão (Org). Paixão Pagu: uma autobiografia precoce de Patrícia Galvão. Rio de Janeiro: Agir, 2005.

LOBO, Mara. Parque Industrial. Rio de janeiro: José Olympio, 2006.

MULHERES do Brasil: o manifesto da União Feminina do Brasil, Diário da Bahia, Salvador, 03 jul. 1935. p. 3.

O INVESTIGADOR n. 586 descreve a reunião dos elementos da União Feminina. Diário da Bahia, Salvador, 10 jan. 1936. p. 2. 
PAGÚ. Malthus Além. Homem do Povo. 27 mar. 1931. p. 2. Disponível em: < http://bndigital.bn.br/hemeroteca-digital/> Acesso em: 20 abr. 2016.

RAMOS, Graciliano. Memórias do Cárcere, vol. 1. Rio de janeiro/São Paulo: Record, 1986.

WERNECK, MARIA. Sala 4: primeira prisão política feminina. Rio de Janeiro: CESAC, 1988.

\section{Bibliografia}

ALVES, Iracélli da Cruz.A política no feminino: uma história da militância feminina no partido Comunista do Brasil - Seção Bahia (1942-1949). 2015. 240 f. (Dissertação) História Departamento de Ciências Humanas e Filosofia. Universidade Estadual de Feira de Santana (UEFS), Feira de Sanatana, 2015. Disponível em: <http://www2.uefs.br/pgh/banco.html> Acesso em: 26 abri. 2016.

DEMIER, Felipe. O longo bonapartismo brasileiro (1930-1964): um ensaio de interpretação histórica. Rio de Janeiro: Mauad X, 2013.

MORAES, Maria Lygia Quartim. A solidão de Pagu. In: FERREIRA, Jorge; REIS, Daniel Aarão (Orgs.) A formação das tradições (1889-1945). Vol. 1. Rio de Janeiro: Civilização Brasileira, 2007. p. 365-378.

PINTO, Céli Regina Jardim. Uma história do feminismo no Brasil. São Paulo: Perseu Abramo, 2003.

RAGO, Elisabeth Juliska. Outras Falas: feminismo e medicina na Bahia (1836-1931). São Paulo: Annablume/FAPESP, 2007a.

RAGO, Margareth. A aventura de contar-se: feminismos, escrita de si e invenções de subjetividade. Campinas: Editora da Unicamp, 2013.

RAGO, Margareth. Entre a história e a liberdade: Luce Fabri e o anarquismo contemporâneo. São Paulo: UNESP, 2001.

RAGO, Margareth. Ética, anarquia e revolução em Maria Lacerda de Moura. In: FERREIRA, Jorge; REIS, Daniel Arão (Orgs.). A formação das tradições (1889-1945). v. 1. Rio de Janeiro: Civilização Brasileira, 2007b. p. 262-293.

SENA JUNIOR, Carlos Zacarias. Os impasses da estratégia: os comunistas, o antifascismo e a revolução burguesa no Brasil. 1936-1948. São Paulo: Annablume, 2009.

SIQUEIRA, Tatiana Lima de. Impressões Feministas: discursos sobre o feminismo no Diário da Bahia (1931-1937). 2009. 123f. (Dissertação) Estudos Interdisciplinares sobre Mulheres, Gênero e Feminismo - Departamento de Filosofia e Ciências Humanas, Universidade Federal da Bahia (UFBA), Salvador, 2009. Disponível em: Acesso em: Disponível em: < https://repositorio.ufba.br/ri/handle/ri/9944 > Acesso em: 13 mar. 2016. 
SOIHET, Rachel. Feminismos e antifeminismos. Mulheres e suas lutas pela conquista da cidadania plena. Rio de janeiro: 7Letras, 2013.

VIEIRA, Cláudia Andrade. Mulheres de elite em movimento por direitos políticos: o caso de Edith Mendes da Gama e Abreu. 2002. 182 f. (Dissertação) História - Departamento de História. Pontifica Universidade Católica de São Paulo (PUC-SP), São Paulo, 2002.

ARTIGO ENVIADO EM: 04/05/2016 ARTIGO ACEITO PARA PUBLICAÇÃO EM: 11/08/2016 